\title{
Differential proteomic analysis of the secretome of Irpex lacteus and other white-rot fungi during wheat straw pretreatment
}

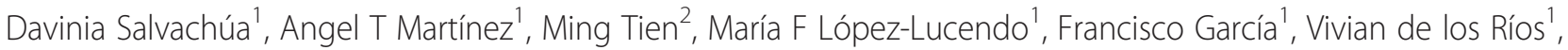 \\ María Jesús Martínez ${ }^{1 *}$ and Alicia Prieto ${ }^{1 *}$
}

\begin{abstract}
Background: Identifying new high-performance enzymes or enzyme complexes to enhance biomass degradation is the key for the development of cost-effective processes for ethanol production. Irpex lacteus is an efficient microorganism for wheat straw pretreatment, yielding easily hydrolysable products with high sugar content. Thus, this fungus was selected to investigate the enzymatic system involved in lignocellulose decay, and its secretome was compared to those from Phanerochaete chrysosporium and Pleurotus ostreatus which produced different degradation patterns when growing on wheat straw. Extracellular enzymes were analyzed through 2D-PAGE, nanoLC/MS-MS, and homology searches against public databases.
\end{abstract}

Results: In wheat straw, I. lacteus secreted proteases, dye-decolorizing and manganese-oxidizing peroxidases, and $\mathrm{H}_{2} \mathrm{O}_{2}$ producing-enzymes but also a battery of cellulases and xylanases, excluding those implicated in cellulose and hemicellulose degradation to their monosaccharides, making these sugars poorly available for fungal consumption. In contrast, a significant increase of $\beta$-glucosidase production was observed when I. lacteus grew in liquid cultures. P. chrysosporium secreted more enzymes implicated in the total hydrolysis of the polysaccharides and $P$. ostreatus produced, in proportion, more oxidoreductases.

Conclusion: The protein pattern secreted during I. lacteus growth in wheat straw plus the differences observed among the different secretomes, justify the fitness of I. lacteus for biopretreatment processes in 2G-ethanol production. Furthermore, all these data give insight into the biological degradation of lignocellulose and suggest new enzyme mixtures interesting for its efficient hydrolysis.

Keywords: Enzymatic hydrolysis, Bioethanol, DyP, Pleurotus ostreatus, Phanerochaete chrysosporium, Lignocellulose, Extracellular enzymes

\section{Background}

In the fungal kingdom, white-rot fungi (phylum Basidiomycota) are the only microorganisms known to be able to alter all plant components, including lignin, cellulose, and hemicellulose [1]. The applicability of this potential for a number of biotechnological processes, for instance, as a tool for lignocellulose pretreatment in second-generation ethanol production processes, has been suggested [2]. However, for this purpose, the

\footnotetext{
*Correspondence: mjmartinez@cib.csic.es; aliprieto@cib.csic.es

${ }^{1}$ Centro de Investigaciones Biológicas, CSIC, Ramiro de Maeztu 9, E-28040

Madrid, Spain

Full list of author information is available at the end of the article
}

degrading microorganisms should display some desirable features, such as consuming low sugar for its own growth and promoting a high lignocellulose deconstruction, to render more accessible polysaccharides for enzymatic hydrolysis and thus increase fermentable sugar yields. To date, considering these fundamentals, very few fungi have been shown to be adequate for biological pretreatment in this type of processes [3].

The white-rot fungus I. lacteus can degrade different lignocellulosic substrates (e.g. corn stalks/stover or wheat straw) yielding high sugar recoveries compared to other fungal treatments [3-6]. Furthermore, a positive effect on glucose yields from lignocellulosic substrates has been

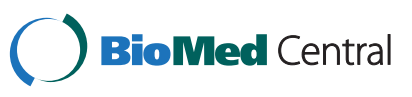


reported when $\mathrm{Mn}^{2+}$ was added in I. lacteus cultures $[7,8]$. This extraordinary capacity is mainly the result of a high metabolic versatility and secretory potential. While different sets of hydrolytic enzymes are implicated in this process, the pool of proteins secreted by I. lacteus during the biopretreatment of a lignocellulosic substrate remains unknown.

Secretomic analysis, apart from being an excellent method to understand the biological mechanisms of lignocellulose degradation, is a valuable tool in the search for new enzymes or interesting enzyme complexes in the biofuels field $[9,10]$. For this reason, publications documenting fungal secretomes have increased in recent years. Most of them have been performed with ascomycetes and are focused on enhancing the enzymatic hydrolysis of lignocelluloses more than on the pretreatment step $[11,12]$. Among the few reports concerning basidiomycetes, nearly all have dealt with the secretome of $P$. chrysosporium grown under several culture conditions [13-15], since the genome of this organism is available from 2004 [16]. However, due to the rapid growth of genome sequencing and the associated ability to perform protein homology searches, the secretome database of basidiomycetes is currently enlarging. To cite some examples, the secretomes from Pleurotus sapidus growing in submerged cultures either on peanut shells or on glass wool [17], Phanerochaete carnosa on spruce [18], Ganoderma lucidum on sugarcane bagasse [19], and Trametes trogii on Populus wood [20] have been reported.

The aims of the current work are to get a deeper understanding on the dynamics of wheat straw degradation by $I$. lacteus over the time and to search for interesting enzymes and/or enzyme complexes for biopretreatment and enzymatic hydrolysis processes. In addition, the I. lacteus secretome's composition after 21 days of solid state fermentation (SSF) on wheat straw, in the presence and absence of $\mathrm{Mn}^{2+}$, will be compared to that released either in liquid cultures of the same fungus or in SSF cultures of two white-rot fungi, $P$. chrysosporium and $P$. ostreatus, grown on the same substrate. The latter fungi cause different wheat straw degradation patterns when cultured under SSF conditions [3] and offer the additional advantage of having their genome sequences available. Advanced proteomic technologies, such as high-throughput nano-high performance liquid chromatography-tandem mass spectrometry (nanoLC-MS/MS), have been used to provide information on the physiology, diversity, enzyme interactions, and even kinetics of the expression profiles over the time, either from whole secretomes and from proteins isolated in two dimensional (2D)-gels.

\section{Results and discussion}

The most significant hits from the proteins isolated from the 2D-gels, in terms of score and sequence coverage from both databases, are gathered in Additional file 1: Table S1. Protein identities provided on the basis of a single matching peptide, were considered as tentative. The functional classifications of the proteins identified from the extracellular pool of proteins (EPP) analyses, from JGI and Uniprot databases, are collected in Additional file 1: Tables S2-S9.

Before discussing the experimental results, some general considerations should be laid down. In the case of 2D-gels, MS/MS analyses showed that a protein can be identified in several independent spots. In some cases this observation may be the result of the coexistence of different isoforms or closely related gene products [21], but the presence of protein fragments from proteolytic cleavage cannot be ruled out. In fact, some extracellular proteases, which may have digested susceptible proteins either in cultures or during sample preparation, have been identified in the present work. In addition, some spots contain more than one molecular species. A probable cause is co-migration of protein fragments with other full length proteins. It is also possibly due to streaking of proteins observed in certain areas of the gels, presumably because of the impossibility of getting completely rid of a pigmented material contained in the extracts produced under SSF conditions. Additionally, it is worth mention that the correlation of the predicted molecular mass (MM) and/or pI of the hits with the values deduced from gels for each spot is not always accurate. This can be due to (1) a differential pattern of post-translational modifications, such as glycosylation, and (2) a match with a homologous protein from a different species.

\section{Secretome of I. lacteus growing on wheat straw} Comparative analysis of the proteins secreted over the time I. lacteus degrades simultaneously all components of wheat straw (Table 1). The biopretreated product keeps high sugar concentration with improved accessibility for further enzymatic hydrolysis aimed to second-generation ethanol production [3]. In order to study the major enzymes involved in the degradation of wheat straw and to investigate their variations over the time, the secretome of I. lacteus after 7, 14, and 21-d SSF was isolated and a comparative analysis, using 2D-PAGE, was performed. The spot pattern proved to be highly reproducible in replicate cultures. Gels from control cultures (without fungus) did not show any spot (data not shown). Most proteins focused in a $\mathrm{pH}$ range of 3-6 and had molecular masses from 37 to $100 \mathrm{kDa}$, a profile similar to those reported for other basidiomycetes [14]. The evolution of enzymes release, concerning both the number of different molecular species and the amount of the proteins detected at different growth stages, can be observed by simple visual inspection of the gels images (Figure 1a-c). The one 
Table 1 Summary of wheat straw components degradation, digestibility, and sugar yields after biopretreatment processes

\begin{tabular}{|c|c|c|c|c|c|c|c|c|}
\hline & \multirow[b]{2}{*}{ Days } & \multicolumn{3}{|c|}{ Loss (\% initial content) } & \multicolumn{2}{|c|}{ Digestibility (\%) } & \multicolumn{2}{|c|}{ Sugar yields (\%) } \\
\hline & & CEL & HEM & LIG & CEL & HEM & GLU & $\mathrm{XYL}$ \\
\hline I. lacteus & 7 & $9 \pm 0$ & $13 \pm 7$ & $11 \pm 0$ & $28 \pm 4$ & $32 \pm 8$ & $24 \pm 2$ & $28 \pm 7$ \\
\hline I. lacteus & 14 & $17 \pm 1$ & $13 \pm 4$ & $27 \pm 1$ & $56 \pm 6$ & $71 \pm 5$ & $46 \pm 1$ & $61 \pm 1$ \\
\hline I. lacteus & 21 & $21 \pm 2$ & $23 \pm 2$ & $36 \pm 1$ & $78 \pm 4$ & $78 \pm 2$ & $62 \pm 2$ & $61 \pm 4$ \\
\hline I. lacteus+ $\mathrm{Mn}^{2+}$ & 21 & $18 \pm 1$ & $45 \pm 6$ & $38 \pm 1$ & $82 \pm 3$ & $99 \pm 8$ & $68 \pm 2$ & $55 \pm 6$ \\
\hline P. chrysosporium & 21 & $35 \pm 0$ & $70 \pm 24$ & $0 \pm 0$ & $15 \pm 0$ & $22 \pm 0$ & $9 \pm 0$ & $7 \pm 6$ \\
\hline P. ostreatus & 21 & $22 \pm 1$ & $52 \pm 13$ & $27 \pm 1$ & $55 \pm 3$ & $52 \pm 8$ & $42 \pm 3$ & $30 \pm 9$ \\
\hline Control* & 21 & $0 \pm 0$ & $0 \pm 0$ & $0 \pm 0$ & $36 \pm 6$ & $35 \pm 5$ & $36 \pm 6$ & $35 \pm 5$ \\
\hline
\end{tabular}

Cellulose (CEL), hemicellulose (HEM), and lignin (LIG) losses from wheat straw pretreatment (SSF cultures) with I. lacteus (different times and Mn ${ }^{2+}$ supplementation), $P$. chrysosporium and $P$. ostreatus are depicted. Cellulose and hemicellulose digestibilities (from sugar release referred to the biotreated material) and glucose $(G L U)$ and xylose $(X Y L)$ recoveries (as fermentable sugars referred to the initial straw) are also shown. From Salvachúa et al. [3,7].

"Non-biopretreated wheat straw.

from the 21-d secretome did not only display the maximum spots number, but also contained all spots detected in the gels of samples from 7-d and 14-d SSF. Then, the spots from the 21-d gel (Figure 1c), were chosen to be excised, in-gel digested, and subjected to MS/MS analysis for protein identification.

Most of the hits that allowed the identification of $I$. lacteus proteins were from Uniprot (Table 2). Concerning the secretome composition over the time, $70 \%$ of the spots were already produced during the first week of incubation (Figure 1a). The major enzymes at this stage (Table 2) were involved in cellulose (endoglucanases and exocellulases), hemicellulose (acetyl xylan esterases and endo-1,4$\beta$-xylanase), and protein degradation. It is worth pointing out that for complete cellulose degradation, the concerted action of three cellulolytic activities is required: endoglucanases, which hydrolyze internal 1,4- $\beta$-bonds; cellobiohydrolases I and II (CBHI and CBHII), which act in a

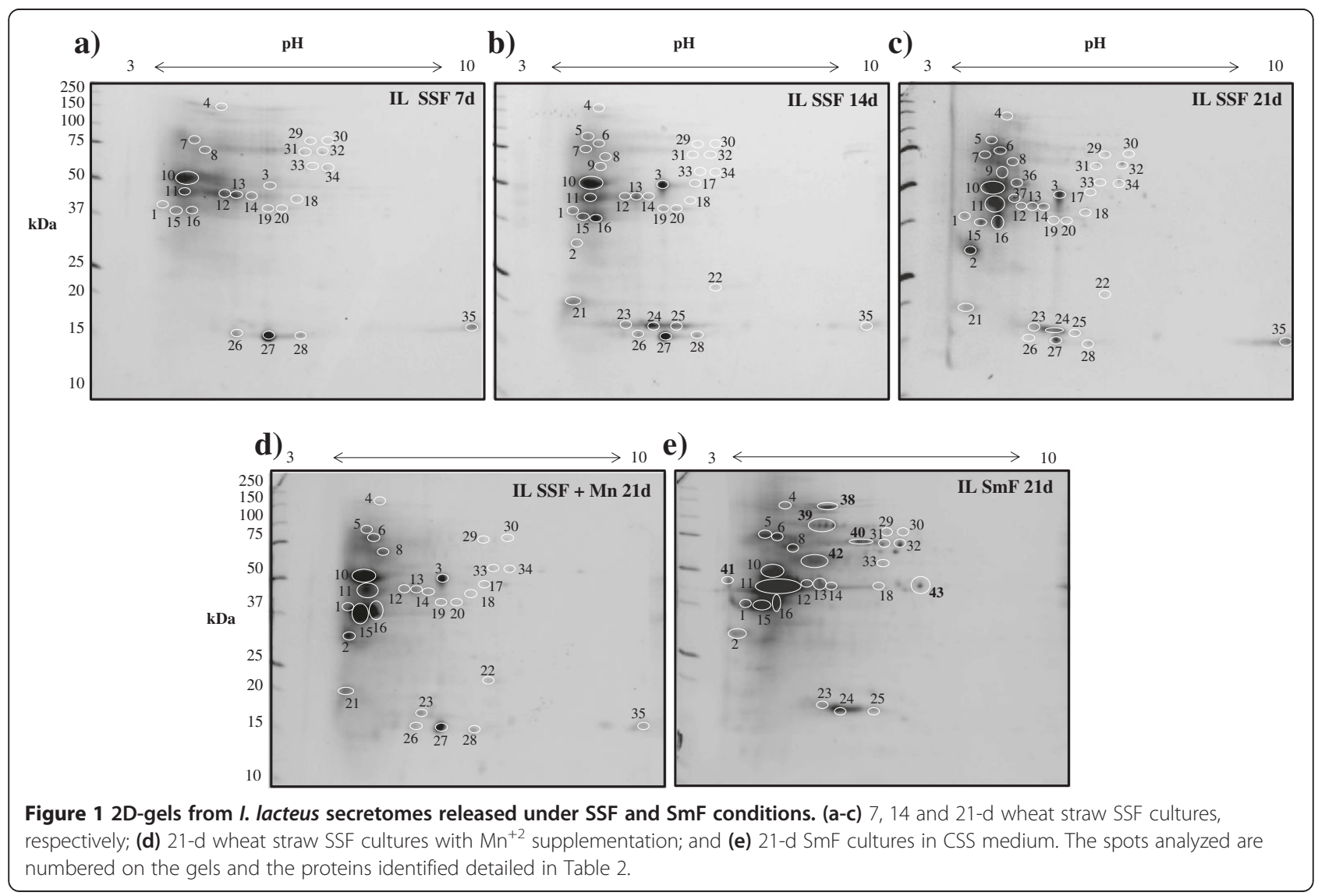


Table 2 Protein identification from 2D-gel spots from I. lacteus secretomes in SSF and SmF cultures

\begin{tabular}{|c|c|c|c|c|c|c|c|c|c|c|}
\hline Spot & Day $^{1}$ & $\mathrm{SmF}^{2}$ & $\mathrm{Mn}^{3}$ & Predicted protein function & Species $^{4}$ & Protein ID & $\mathrm{MM}(\mathrm{kDa})$ & $\mathrm{pl}$ & Score & $U P^{5}$ \\
\hline 1 & 7 & + & + & Cellobiohydrolase II & $\mathrm{IL}$ & B2ZZ24 & 47.2 & 5.3 & 20.6 & 4 \\
\hline 2 & 14 & + & + & Cellulase & $\mathrm{IL}$ & Q9Y724 & 55.8 & 4.6 & 13.9 & 3 \\
\hline 3 & 7 & & + & Rhamnogalacturonan-hydrolase & $\mathrm{IL}$ & B6E8Y7 & 46.7 & 6.9 & 17.4 & 3 \\
\hline 4 & 7 & + & + & Cellobiohydrolase & IL & Q75NB5 & 54.8 & 5.3 & 15.4 & 4 \\
\hline 5 & 14 & + & + & Cellulase & $\mathrm{IL}$ & Q9Y724 & 55.8 & 4.6 & 215.8 & 10 \\
\hline 6 & 14 & + & + & Cellulase & IL & Q9Y724 & 55.8 & 4.6 & 85.3 & 7 \\
\hline 7 & 7 & & & Cellulase & IL & Q9Y724 & 55.8 & 4.6 & 139.4 & 11 \\
\hline 8 & 7 & + & + & Cellobiohydrolase & $\mathrm{IL}$ & Q75NB5 & 54.8 & 5.3 & 66.7 & 8 \\
\hline 9 & 14 & & & Cellobiohydrolase II & $\mathrm{IL}$ & B2ZZ24 & 47.2 & 5.3 & 90.9 & 7 \\
\hline 10 & 7 & + & + & Cellobiohydrolase II & IL & B2ZZ24 & 47.2 & 5.3 & 46.0 & 7 \\
\hline 11 & 7 & + & + & Cellobiohydrolase II & $\mathrm{IL}$ & B2ZZ24 & 47.2 & 5.3 & 25.2 & 5 \\
\hline 12 & 7 & + & + & Endoglucanase & IL & Q5W7K4 & 42.2 & 4.9 & 15.4 & 3 \\
\hline 13 & 7 & + & + & Acetyl xylan esterase & $P C$ & H2ESB9 & 38.9 & 6.5 & 12.9 & 2 \\
\hline 14 & 7 & + & + & Acetyl xylan esterase & $P C$ & H2ESB9 & 38.9 & 6.5 & 15.5 & 2 \\
\hline 15 & 7 & + & + & Polyporopepsin & $\mathrm{IL}$ & P17576 & 35.0 & 4.7 & 20.0 & 5 \\
\hline 16 & 7 & + & + & Aspartic protease & PN & G3XKT3 & 42.8 & 5.5 & 70.0 & 2 \\
\hline 17 & 14 & & + & Rhamnogalacturonan-hydrolase & IL & B6E8Y7 & 46.7 & 6.9 & 27.3 & 6 \\
\hline 18 & 7 & + & + & Acetyl xylan esterase & PC & H2ESB9 & 38.9 & 6.5 & 27.9 & 2 \\
\hline 19 & 7 & & + & Cellobiohydrolase II & IL & B2ZZ24 & 47.2 & 5.3 & 4.1 & 2 \\
\hline 20 & 7 & & + & Endo-1,4- $\beta$-xylanase A & PC & Q9HEZ1 & 43.5 & 5.4 & 3.1 & 1 \\
\hline 21 & 14 & & + & Putative protein hypP2 & MP & Q6U7U4 & 47.9 & 8.7 & 6.1 & 1 \\
\hline 22 & 14 & & + & Putative protein hypP2 & MP & Q6U7U4 & 47.9 & 8.7 & 6.0 & 1 \\
\hline 23 & 14 & + & + & Aspartic protease & PN & G3XKT3 & 42.8 & 5.5 & 3.9 & 1 \\
\hline 24 & 14 & + & & Aspartic protease & PN & G3XKT3 & 42.8 & 5.5 & 3.7 & 1 \\
\hline 25 & 14 & + & & Putative protein & $P G$ & E3JYEO & 21.2 & 6.3 & 2.7 & 1 \\
\hline 26 & 7 & & + & Aspartic protease & PN & G3XKT3 & 42.8 & 5.5 & 3.9 & 1 \\
\hline 27 & 7 & & + & Serine-type peptidase ${ }^{6}$ & PS & Punst1 106327 & 59.2 & 4.9 & 53.1 & 1 \\
\hline 28 & 7 & & + & Putative protein hypP2 & MP & Q6U7U4 & 47.9 & 8.7 & 5.6 & 1 \\
\hline 29 & 7 & + & + & Cellulase & IL & Q9Y724 & 55.8 & 4.6 & 9.1 & 2 \\
\hline 30 & 7 & + & + & Cellobiohydrolase & $\mathrm{IL}$ & Q75NB5 & 54.8 & 5.3 & 2.7 & 1 \\
\hline 31 & 7 & + & & Cellobiohydrolase & IL & Q75NB5 & 54.8 & 5.3 & 12.9 & 2 \\
\hline 32 & 7 & + & & Cellobiohydrolase & IL & Q75NB5 & 54.8 & 5.3 & 6.3 & 2 \\
\hline 33 & 7 & + & + & Cellobiohydrolase II & IL & B2ZZ24 & 47.2 & 5.3 & 14.2 & 3 \\
\hline 34 & 7 & & + & Cellobiohydrolase II & IL & B2ZZ24 & 47.2 & 5.3 & 8.5 & 1 \\
\hline 35 & 7 & & + & Histone H4 (Fragment) & MP & E2LLY3 & 8.8 & 11.6 & 5.1 & 1 \\
\hline 36 & 21 & & & Cellobiohydrolase II & $\mathrm{IL}$ & B2ZZ24 & 47.2 & 5.3 & 37.1 & 6 \\
\hline 37 & 21 & + & & Endoglucanase & $\mathrm{IL}$ & Q5W7K4 & 42.2 & 4.9 & 63.1 & 3 \\
\hline 38 & L & + & & GH3/ $\beta$-glucosidase & SP & F8PMW3 & 78.3 & 4.7 & 63.3 & 4 \\
\hline 39 & $L$ & + & & Putative protein & MP & Е2M3Р0 & 13.2 & 4.7 & 3.4 & 1 \\
\hline 40 & L & + & & Glyoxal oxidase ${ }^{6}$ & PS & Punst1 68820 & 59.6 & 5.2 & 1.9 & 1 \\
\hline 41 & L & + & & Polyporopepsin & IL & P17576 & 35.0 & 4.7 & 25.6 & 2 \\
\hline 42 & L & + & & Exo- $\beta$ - $(1 \rightarrow 3)$-galactanase & IL & B9ZZS1 & 16.8 & 47.8 & 6.7 & 4 \\
\hline 43 & L & + & & Mannose-6-phosphatase & $P C$ & Q281W3 & 38.4 & 6.6 & 71.6 & 4 \\
\hline
\end{tabular}

Only the hits with maximal score from Uniprot database are shown (together with two from JGI).

(1) SSF incubation time in which the spot was first detected and differential spots for SmF cultures (L). (2) and (3) + indicates presence of the spot in SmF, and SSF cultures supplemented with a manganese salt, respectively. (4) Species where the protein had been found: IL Irpex lacteus, MP Moniliophthora perniciosa, PC Phanerochaete chrysosporium, PN Pholiota nameko, PO Pleurotus ostreatus, PS Punctularia strigosozonata, and SL Serpula lacrymans. (5) Unique proteins. (6) Proteins identified only using the JGI database. 
synergistic way as exo-cellulases from the reducing and the non-reducing end of the glucidic chain, respectively, releasing cellobiose [15]; and $\beta$-glucosidases, which finally break cellobiose into two glucose monomers [13]. The latter enzyme was not detected in these 2D-gels. The acetyl xylan esterase cleaves acetyl side groups from the hetero-xylan backbone and endo-1,4- $\beta$-xylanase hydrolyzes internal 1,4- $\beta$ bonds of xylan [22]. As occurred with cellulose, these enzymes cannot degrade hemicellulose or xylan polymers completely since $\beta$-xylosidases, arabinofuranosidases, or $\alpha$-glucuronidases, which are also required [23], were not produced by the fungus. Finally, proteases, as polyporopepsin, have been implicated in the activation of cellulases, in the cleavage of functional domains of cellobiose dehydrogenases (CDH) [24], and also in trapping nitrogen in lignocellulose under nitrogen-starvation conditions [14].

After the second SSF week, almost all spots from the major proteins detected at the final incubation period were visualized (Figure 1b). Rhamnogalacturonanhydrolase (spot 17) and different isoforms of cellulases (spots 2, 5, 6, 9) were produced. A very faint spot from pectinase was first observed in 7-d gels (spot 3), but an intense secretion of this protein was detected from two incubation weeks onwards in spite of the fact that pectin content in lignocellulosic materials is low. In parallel, many small-sized proteins came into view. The JGI database matched some of them (spots 21,22, 25, and 28) to cerato-platanin or Barwin-related endoglucanases. These proteins, secreted by a number of non-pathogenic and pathogenic fungal species when interacting with plant or animal cells, are involved in cell wall biogenesis or degradation [25].

In the 21-d secretome, two new spots $(36,37)$ were observed, matching respectively with CBHII and endoglucanase (Table 2). A total of 37 spots and 18 different proteins were identified. The protein spot intensity of some cellulases (spots 2, 5, 6, 7, 8, 9, and 11) and an aspartic proteinase (spot 16), probably similar to the polyporopepsin and other aspartic proteases already detected in the 14-d SSF samples, were much more intense in the 21-d sample.

The proteins identified using both databases (Additional file 1: Table S1) are in good agreement in most cases, and the presence of several proteins in some spots insufficiently separated in the gel can be inferred from the data displayed in this table. For example, spot 10, heavily stained in all gels (Figure 1a-c) probably contains a mixture of proteins. The hits returned with maximal scores from JGI and Uniprot corresponded to manganese peroxidase $(\mathrm{MnP})$ and $\mathrm{CBHII}$, respectively, suggesting that both proteins are present in the crude and migrate together. $\mathrm{MnP}$ causes the cleavage of $\mathrm{C}-\mathrm{C}$ and $\mathrm{C}-\mathrm{O}$ bonds between phenolic lignin units, and this enzyme activity is frequently found in lignocellulose-degradation processes by I. lacteus [26].

\section{Analysis of the 21-d I. lacteus EPP}

The analysis of the secretome released after growing $I$. lacteus on wheat straw for 21-d using a shotgun proteomics approach was an excellent complement to confirm the data from 2D-gels and disclose the presence of extracellular proteins virtually undetectable by other techniques. The results from the search against the basidiomycota database of Uniprot (Additional file 1: Table S2) identified 34 different proteins, of which 11 hits corresponded to I. lacteus enzymes. Most of them are involved in lignocellulose degradation and were functionally classified, according to their biological role, such as glycoside hydrolases (GHs), oxidoreductases, esterases, proteases, phosphatases, and proteins with other or unknown functions (Figure 2). The 45 hits identified from the search using the JGI database (Additional file 1: Table S3) corresponded to enzymes from related basidiomycetes, with similar functionalities to those returned by Uniprot.

Table 3 summarizes the ten extracellular proteins (Top-10) identified with maximal scores from Uniprot database. This set of proteins rather agrees with the most intense spots in 2D-gels (e.g. CBHII, cellulases, and proteases had the highest scores and spot intensities, respectively) and was in accordance with previous reports comparing both methodologies [27]. However, some new proteins were identified that may be relevant for enzymatic decay of wheat straw. Among them, a $\mathrm{Mn}^{2+}$-oxidizing and melanin-decolorizing enzyme ( $\left.\mathrm{MnP}\right)$ [28], an exo- $\beta-1,3$-galactanase, implicated in hemicellulose degradation and isolated by Tsumuraya et al. [29] from this fungus, and a hypothetical peroxidase (cpop21) from a member of the Polyporaceae family, can be highlighted. A recent report from Salvachúa et al. [30] described the purification from I. lacteus liquid cultures of a dyedecolorizing peroxidase (DyP), able to degrade azo- and antraquinone-dyes and phenolic and non-phenolic compounds. The protein was analyzed by MALDI-TOF-MS/ MS, giving 95\% homology with cpop21. Our results here show for the first time DyP production during SSF on wheat straw, a natural lignocellulosic environment.

Several additional proteins were also detected in the EPP of I. lacteus. The most significant were glyoxal oxidase (which is a copper radical oxidase) and $\mathrm{CDH}$ (Additional file 1: Tables S2 and S3). These two enzymes are oxidoreductases able to produce the $\mathrm{H}_{2} \mathrm{O}_{2}$ required for the action of extracellular peroxidases [17]. Moreover, $\mathrm{CDH}$ has also been implicated in: i) generating highly-reactive hydroxyl radicals via Fenton chemistry [15]; ii) binding cellulose, which probably enhances cellulase activities by relieving product inhibition [24]; and 


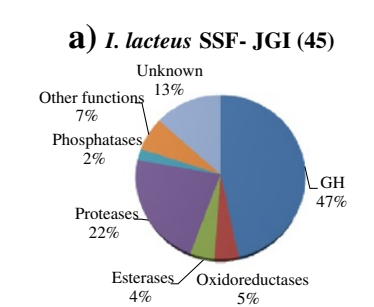

e) P. chrysosporium SSF- JGI (187)

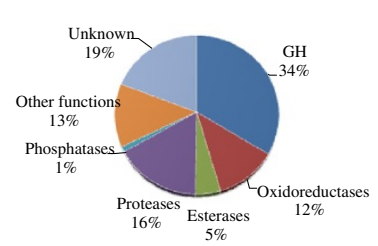

b) I. lacteus SSF- Uniprot (34)

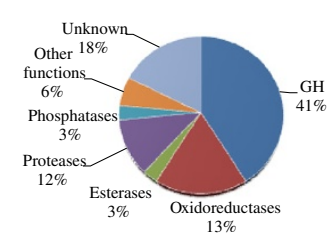

f) P. chrysosporium SSF- Uniprot (33)

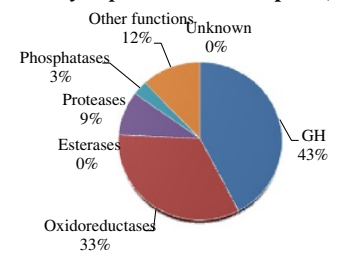

c) I. lacteus SmF - JGI (53)

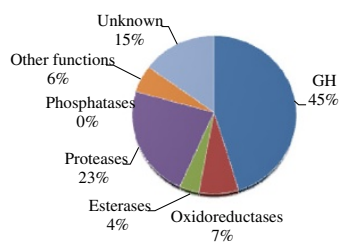

g) P. ostreatus SSF - JGI (164)

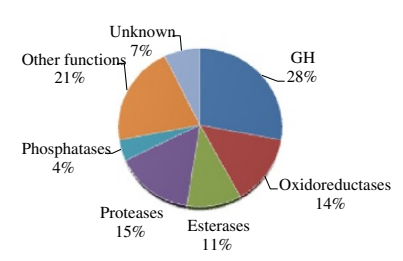

d) I. lacteus SmF- Uniprot (30)

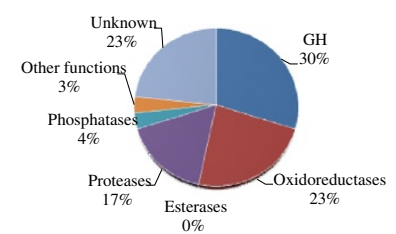

h) P. ostreatus SSF- Uniprot (17)

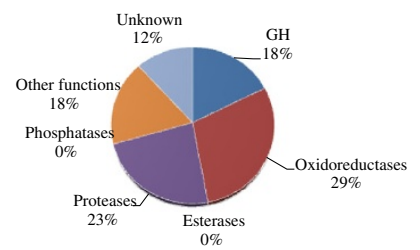

Figure 2 Functional classification of the lignocellulose-degrading enzymes found in the secretomes, according to Uniprot and JGI searches. Groups of proteins released by I. lacteus grown on wheat straw (a-b) or in submerged cultures (c-d), and in SSF cultures P. chrysosporium (e-f) and P. ostreatus ( $\mathbf{g}-\mathbf{h}$ ). The total number of protein matches from JGl and Uniprot databases (Additional file 1: Tables S2-S9) is shown in parenthesis. Basidiomycota databases were used for I. lacteus secretome searches. The results from $P$. chrysosporium and $P$. ostreatus were searched against their own databases. SSF= solid state fermentation on wheat straw; SmF= submerged cultures in CSS; GH= glycosil hydrolases.

iii) preventing phenoxy radical-dependent re-polymerization of lignin [13]. Finally, other hits corresponded to putative uncharacterized proteins whose functions, still unknown, could be assumed to be related to lignocellulose degradation.

\section{Secretome of $I$. lacteus growing on different culture conditions \\ $\mathrm{Mn}^{2+}$-supplemented wheat straw}

The supplementation with $\mathrm{Mn}^{2+}$ during I. lacteus pretreatment is known to improve the enzymatic hydrolysis yields of wheat straw (Table 1). In this study, a 2D-PAGE differential analysis of the enzymes secreted by I. lacteus, growing for 21-d on wheat straw supplemented or not with a $\mathrm{Mn}^{2+}$ salt, was performed (Figure $1 \mathrm{~d}$ and 1c). The enzymatic profiles were similar in both cases, and new spots were not observed. However, some proteins were missing in cultures with added $\mathrm{Mn}^{2+}$. Most of them (spots $7,9,31,32,36,37)$ corresponded to cellulose-degrading enzymes. In parallel, spot 15 , which was identified as polyporopepsin in 2D-gels of 21-d SSF basal cultures, was intensely stained indicating either an increased secretion of this protein or the release of a different enzyme that comigrated with the peptidase. This spot was analyzed and a mixture of polyporopepsin (similar to that of Pholiota nameko) and MnP (similar to that of Lenzites gibbosa) was identified with scores around 50, indicating that the latter enzyme was induced by $\mathrm{Mn}^{2+}$. In addition, the MM and $\mathrm{pI}$ of the overexpressed $\mathrm{MnP}$ protein coincided with those reported for a MnP from I. lacteus [26]. Surprisingly, the increase of MnP production did not enhance significantly lignin degradation. On the contrary, an extensive hemicellulose loss was observed in these cultures, which could be due to the unspecific degradation of this polymer through $\mathrm{Mn}^{2+}$-mediated oxidative reactions [32].

\section{Submerged cultures}

The enzyme production in a non-lignocellulosic medium (CSS) under SmF culture conditions was studied at long incubation times $(21 \mathrm{~d})$ mimicking $\mathrm{N}$ - and C-limitation, using the same proteomic tools applied for SSF secretomes. The enzyme pattern in SmF (Figure 1e) and SSF (Figure 1c), revealed the differences between the two culture conditions. Whereas many cellulases, $\mathrm{CBHs}$, and proteases were produced under both conditions, six new intense spots emerged in SmF (spots 38-43), whose identities are given in Table 2. Among them, the most heavily stained (spot 38) matched with a $\beta$-glucosidase. In contrast, the spots corresponding to rhamnogalacturonanhydrolases, endo-1,4- $\beta$-glucanases, endo-1,4- $\beta$-xylanases, some cellulases, and CBHII were missing in SmF cultures (Table 2). Obviously, the production of such a wide battery of cellulases and hemicellulases is not required in a medium without lignocellulose. As expected, spots 21, 22, and 28 from ceratoplatanins neither appeared.

NanoLC-MS/MS identification of the proteins from the whole EPP is presented in Additional file 1: Tables S4 and S5 and the ten extracellular proteins identified with maximal scores (Top-10) using Uniprot database are gathered in Table 3. Some of these enzymes are specially interesting: (1) polyporopepsin, which can be implicated in protein degradation, supplying nitrogen for fungal growth, (2) mannose-6-phosphatase, which has been shown to be involved in the extracellular dephosphorylation of enzymes in carbon-starved cultures [33] and ribonuclease T2, that 
Table 3 Summary of the ten extracellular proteins (Top-10) identified with maximal scores from the shotgun analysis

\begin{tabular}{|c|c|c|c|c|c|c|c|}
\hline EPP & Predicted protein function & Species $^{1}$ & ID & $\mathrm{MM}(\mathrm{kDa})$ & pl & Score & UP $^{2}$ \\
\hline I. lacteus & Cellobiohydrolase II & $\mathrm{IL}$ & B2ZZ24 & 47.2 & 5.3 & 606.0 & 13 \\
\hline \multirow[t]{9}{*}{ SSF } & Polyporopepsin & $\mathrm{IL}$ & P17576 & 35.0 & 4.7 & 307.2 & 8 \\
\hline & Cellulase & $\mathrm{IL}$ & Q9Y724 & 55.8 & 4.6 & 193.3 & 9 \\
\hline & Acetyl xylan esterase & PC & H2ESB9 & 38.9 & 6.5 & 142.2 & 2 \\
\hline & Melanin-decolorizing enzyme $(\mathrm{MnP})^{3}$ & $\mathrm{Ce}$ & B3IWB3 & 38.3 & 5.1 & 142.1 & 10 \\
\hline & Peroxidase cpop21 (DyP1) ${ }^{4}$ & $\mathrm{IL}$ & P87212 & 53.9 & 5.0 & 122.2 & 8 \\
\hline & Endoglucanase & $\mathrm{IL}$ & Q5W7K4 & 42.2 & 4.9 & 118.3 & 3 \\
\hline & Cellobiohydrolase & $\mathrm{IL}$ & Q75NB5 & 54.8 & 5.3 & 106.0 & 11 \\
\hline & Exo- $\beta-(1 \rightarrow 3)$-galactanase & $\mathrm{IL}$ & B9ZZS1 & 47.8 & 6.7 & 99.8 & 8 \\
\hline & Rhamnogalacturonan-hydrolase & $\mathrm{IL}$ & B6E8Y7 & 46.7 & 6.9 & 84.5 & 10 \\
\hline I. lacteus & Polyporopepsin & $\mathrm{IL}$ & P17576 & 35.0 & 4.7 & 4867.5 & 13 \\
\hline \multirow[t]{9}{*}{ SmF } & Peroxidase cpop21 (DyP1) ${ }^{4}$ & $\mathrm{IL}$ & P87212 & 53.9 & 5.0 & 684.8 & 13 \\
\hline & Melanin-decolorizing enzyme $(\mathrm{MnP})^{3}$ & $\mathrm{Ce}$ & B3IWB3 & 38.3 & 5.1 & 368.6 & 11 \\
\hline & Exo- $\beta-(1 \rightarrow 3)$-galactanase & $\mathrm{IL}$ & B9ZZS1 & 47.8 & 6.7 & 202.2 & 11 \\
\hline & Ribonuclease T2 & $\mathrm{IL}$ & Q8LW55 & 41.8 & 5.1 & 137.4 & 4 \\
\hline & Glycoside hydrolase family 3 & $S L$ & F8NLG7 & 89.6 & 5.0 & 130.3 & 1 \\
\hline & Glycoside hydrolase family 3 & $S L$ & F8PMW3 & 78.3 & 4.7 & 111.6 & 2 \\
\hline & Mannose-6-phosphatase & PC & Q281W3 & 38.4 & 6.6 & 87.5 & 3 \\
\hline & Aspartic protease & PN & G3XKT3 & 42.8 & 5.5 & 63.7 & 3 \\
\hline & Manganese peroxidase & LG & H2D7E4 & 38.6 & 4.5 & 56.7 & 3 \\
\hline P. chrysosporium & Manganese peroxidase 3 & PC & Q1K9D0 & 39.8 & 4.6 & 348.7 & 8 \\
\hline \multirow[t]{9}{*}{ SSF } & Glucan 1,3- $\beta$-glucosidase & PC & Q2Z1W1 & 82.0 & 5.8 & 327.6 & 8 \\
\hline & Cellulase & PC & Q7LIJO & 53.8 & 4.9 & 286.6 & 13 \\
\hline & Copper radical oxidase & PC & Q0ZKA8 & 67.8 & 5.5 & 265.8 & 11 \\
\hline & Endo-1,4- $\beta$-xylanase A & PC & Q9HEZ1 & 43.5 & 5.4 & 209.8 & 4 \\
\hline & Cellobiohydrolase II (fragment) & PC & H3K419 & 46.3 & 5.1 & 189.6 & 6 \\
\hline & Endo-1,4- $\beta$-xylanase $C$ & PC & B7SIW2 & 42.3 & 4.9 & 151.9 & 6 \\
\hline & Family S53 protease & PC & Q281W2 & 58.4 & 4.9 & 133.8 & 3 \\
\hline & Exoglucanase 1 & PC & P13860 & 54.8 & 5.5 & 117.1 & 7 \\
\hline & Endo- $\beta$-glucanase & PC & $\mathrm{C} 6 \mathrm{HOM} 6$ & 33.6 & 5.4 & 113.8 & 6 \\
\hline P. ostreatus & Versatile peroxidase $2(\mathrm{VP} 2)^{5}$ & $\mathrm{PO}$ & G8FPZ2 & 38.5 & 4.7 & 629.7 & 8 \\
\hline \multirow[t]{9}{*}{ SSF } & Subtilisin-like protease & $\mathrm{PO}$ & Q6ZYK6 & 93.2 & 5.3 & 330.3 & 11 \\
\hline & Laccase & $\mathrm{PO}$ & Q96TR4 & 57.4 & 6.1 & 284.1 & 9 \\
\hline & Putative protein & $\mathrm{PO}$ & D2JY75 & 27.8 & 6.6 & 162.8 & 7 \\
\hline & Peptidyl-Lys metalloendopeptidase & $\mathrm{PO}$ & P81055 & 17.9 & 6.2 & 118.5 & 5 \\
\hline & Ribonuclease T2 & $\mathrm{PO}$ & Q75NB1 & 41.5 & 6.4 & 65.1 & 4 \\
\hline & a-L-arabinofuranosidase & $\mathrm{PO}$ & G0TES6 & 68.9 & 8.1 & 52.2 & 3 \\
\hline & Putative aspartyl-proteinase (fragment) & $\mathrm{PO}$ & Q96TV7 & 18.5 & 6.2 & 51.8 & 3 \\
\hline & Cellulose 1,4- $\beta$-cellobiosidase & $\mathrm{PO}$ & A5AA53 & 49.3 & 5.6 & 50.6 & 4 \\
\hline & Peptidase 1 & $\mathrm{PO}$ & C4PFY6 & 38.7 & 8.2 & 42.4 & 2 \\
\hline
\end{tabular}

Uniprot database was used for protein identification from the secretomes of the different fungi in SSF and SmF.

(1) Species where the protein had been found. Abbreviations are those used in Table 2, and: Ce Ceriporiopsis sp. and LG Lenzites gibbosa. (2) Unique proteins. (3) Nagasaki et al. [28]. (4) Salvachúa et al. [30]. (5) Camarero et al. [31]. 
can be excreted in response to phosphate starvation for phosphate scavenging from RNA [34], and (3) the peroxidase cpop21 (currently identified as DyP), which can be produced to oxidize more complex molecules to be used as energy/nutrient source. Interestingly, and although not included in the Top-10, a second DyP isoenzyme related to that of Marasmius scorodonius [35] was detected. Some of these enzymes have probably been secreted as a fungal response to survive in cultures $(21 \mathrm{~d})$ limited in essential nutrients. A similar behavior has been previously reported for Pleurotus sapidus in SmF cultures, being peptidolytic and ligninolytic enzymes among the major components of its secretome [17]. Two Mn-oxidizing peroxidases, the socalled melanin-oxidizing enzyme mentioned above and one $\mathrm{MnP}$, were also induced in the $\mathrm{SmF}$ cultures.

Although the relative representation of each enzyme family (\%) in SSF and SmF cultures (Figure 2) was very similar (Additional file 1: Tables S2-S4), the individual proteins were quite different. Comparable expression patterns were described [14] for P. chrysosporium growing in SmF (containing cellulose) and SSF cultures on wood. In contrast, Zorn et al. [17] reported that the production of ligninolytic enzymes by $P$. sapidus was influenced by the presence of lignocellulosic inductors.

\section{Comparative study of the I. lacteus, $P$. ostreatus, and $P$. chrysosporium secretomes growing on wheat straw Fungi, degradation patterns, and databases}

The secretome from 21-d I. lacteus SSF cultures was compared to those from two white-rot fungi, $P$. chrysosporium and $P$. ostreatus. The growth of these species on wheat straw produced different degradation patterns, and the biotreated material gave sugar yields lower than those attained for I. lacteus after enzymatic hydrolysis (Table 1). The MS/MS data from their whole EPP were searched against JGI and Uniprot (Additional file 1: Tables S6-S9). In all cases, the JGI database returned more hits than Uniprot (Figure 2). This is because many hypothetical proteins, deduced from genomic sequences already available, are deposited in that database. Moreover, the percentages yielded for some protein groups were quite different when the inputs from both databases were compared. This is probably due to the fact that many proteins from the JGI have not yet been annotated and may need to be corrected. Even higher differences were found when the number of proteins identified was compared to those predicted from genomes. A total of 769 proteins have been predicted to be part of P. chrysosporium secretome [33]. However, in the current work, 4-fold fewer proteins were detected (around 191). This finding highlights the need of studying secretomes from cultures and not by computational predictions, since the protein set released to the extracellular medium is variable and strongly depends on the environment.
The percentages for the diverse functional groups returned by Uniprot (Figure 2) moderately correlated with the different fungal degradation patterns. P. chrysosporium, which showed a preferential consumption of carbohydrates during biopretreatment of wheat straw (Table 1), produced a wide battery of GHs comprising all the enzymatic set involved in the complete degradation of cellulose and xylan, which suggests that it could be used for improving enzymatic saccharification of wheat straw. This enzymatic profile seemed to be more similar to those from some plant pathogens (e.g. Fusarium verticilloides and Ustilago maydis) than to those from the saprophytes included in this study $[10,11]$. On the contrary, P. ostreatus produced less GHs than oxidoreductases (Figure $2 \mathrm{H}$ ), what can be related to the selectivity towards lignin degradation of Pleurotus species [3].

Finally, $I$. lacteus, inducing the simultaneous degradation of all lignocellulosic components (Table 1), released a percentage of GHs similar to P. chrysosporium, but the amount of extracellular oxidoreductases was lower. Nevertheless, some proteins were detected in the secretomes from the three fungi such as esterases, proteases, and phosphatases. Proteases, whose role has usually been neglected when studying the decay of lignocellulosic substrates, have been found among the Top-10 proteins of the three fungi, seeming to have a great significance for wheat straw deconstruction.

In view of all these results, it can be concluded that the knowledge on the relative proportions of the different enzyme groups is insufficient to discern the mechanisms implicated in fungal degradation. Detailed information on the identity of the main enzymes belonging to each group is required to elucidate these mechanisms.

\section{Oxidoreductases and lignin degradation in wheat straw}

As mentioned above, I. lacteus secreted DyPs, MnPs, CDHs, and glyoxal oxidases in SSF and SmF cultures (Additional file 1: Tables S2, S3, S4, S5). P. chrysosporium released the same enzymes, excluding DyP, but also some others such as lignin peroxidases (LiPs), pyranose 2-oxidase, and GMC oxidoreductases (both producing $\mathrm{H}_{2} \mathrm{O}_{2}$ ) (Additional file 1: Tables S6-S7). MnPs from $P$. chrysosporium were identified with high scores, although this activity was not previously detected in the soluble fraction from cultures on wheat straw [3], which is in accordance with the scarce lignin degradation produced by this fungus. In contrast, $P$. ostreatus secretome contained mostly versatile peroxidase (VP), $\mathrm{MnP}$, laccases, and glyoxal oxidases (Additional file 1: Table S8-S9). The detection of MnP and laccase activities in the extracellular medium of this fungus, growing on wheat straw, had been previously described [3]. Interestingly, the Top-10 peroxidase in the $P$. ostreatus secretome is VP2, the same isoenzyme found in SSF 
cultures of the related Pleurotus eryngii [31]. Cytochrome $\mathrm{P} 450$ and some mono-oxygenases were also identified. These enzymes, whose production has been reported in Phanerochaete carnosa growing on spruce and cellulose, participate in the bioconversion of exogenous aromatic compounds [18].

These results suggest that the diversity of lignindegrading enzymes available in the extracellular matrix does not always run in parallel with the extent of lignin degradation and/or an improvement of the accessibility to carbohydrates in lignocellulose (Table 1). Considering the results obtained for I. lacteus, the combination of $\mathrm{MnP}$ and DyP activities together with glyoxal oxidases and $\mathrm{CDHs}$, which produce $\mathrm{H}_{2} \mathrm{O}_{2}$ for those peroxidases, seems to be a very effective cocktail for biopretreatment of wheat straw.

\section{GHs produced by fungi for wheat straw degradation}

Among the carbohydrate active enzymes (CAZY), the GHs (EC 3.2.1.) are the most widespread group and their classification is currently based on sequence similarities. GHs hydrolyze the glycosidic bonds between two or more carbohydrates or between a carbohydrate and a non-carbohydrate moiety. Their accurate identification is sometimes difficult since many families of GHs do not have functional annotations and contain multiple enzymes. The secretomes from I. lacteus, P. chrysosporium and $P$. ostreatus growing on wheat straw contained enzymes classified into 11, 24 and 30 different $\mathrm{GH}$ families, respectively (Table 4). The GHs secreted by I. lacteus in SmF cultures cluster into 10 different families. Proteins from some groups, such as GH3, GH5, and GH35 were represented in all of the conditions tested in the present study, regardless of the fungal species or the type of culture. These include a variety of enzymes involved in cellulose and hemicellulose degradation. In contrast, hydrolases from families GH6, GH7, GH10, and GH74 were detected exclusively in SSF cultures. Only these four $\mathrm{GH}$ families contain $\mathrm{CBHs}$, suggesting that this type of exocellulases is really induced by lignocellulose.

Many other families of GHs containing starch-degrading enzymes (GH13, GH15, GH31) and pectinases (GH2, GH28) were found in $P$. ostreatus, and several families were only represented in this species. Some of them are GH16, GH55, GH72, GH76, GH78, and GH105, which are mostly implied in fungal metabolism, as for example $\alpha$-mannosidases [36], and GH4, GH51, GH79, and GH115, which include enzymes such as $\alpha$ arabinofuranosidases and $\alpha$-glucuronidases implicated in the complete hydrolysis of hemicellulose [23]. Similarly, proteins from some $\mathrm{GH}$ families were represented in P. chrysosporium $(11,17,18,25,30,71)$, but did not appear in the two other species. Enzymes from the family GH30 are involved in the complete hydrolysis of cellulose and xylan by $\beta$-glucosidases and $\beta$-xylosidases, what implies the extensive sugar consumption during biopretreatment (Table 1).

The GH families detected only in I. lacteus were GH74 in SSF and GH125 in SmF cultures. Proteins from family GH74 have been reported to enhance the performance of complex cell-wall digesting cocktails [37]. The only protein in family GH125 is an exo- $\alpha-1,6$-mannosidase, an enzyme barely described to date [38]. The number of GH families represented in SmF and SSF I. lacteus cultures was similar, although they were quite different from a qualitative point of view. It is worth to emphasize that proteins from family GH30 were detected only in SmF cultures.

The detection of the called "enigmatic" family GH61 in $P$. chrysosporium and I. lacteus should also be pointed out, since proteins from this group have been implicated in the initial steps of lignocelluloses breakdown by white-rot fungi, disrupting the cellulose structure and enhancing its digestibility by cellulases in lignocelluloses [39].

\section{Why I. lacteus is so efficient pretreating wheat straw for 2G-ethanol production?}

Based on the results presented here, we propose that $I$. lacteus degrades cellulose using a large machinery of exocellulases and endoglucanases. Simultaneously, hemicellulose and pectins are mainly being broken down via endo-1,4- $\beta$-xylanase and acetyl xylan esterase, and rhamnogalacturonan hydrolase, respectively. Due to the specific hydrolytic action of these enzymes, large polysaccharide fragments are mostly released. Our results also suggest that the enzymatic action of lignin-degrader oxidoreductases such as $\mathrm{MnP}$ and DyP, and proteases such as polyporopepsin, enhance wheat straw deconstruction by facilitating the action of the carbohydratedegrading enzymes. This enzyme profile yielded easily hydrolysable products with high sugar content. The key of that sugar enrichment is that the extracellular enzymatic pool is deficient in those proteins that catalyze the complete hydrolysis of cellulose and hemicelluloses to their monomeric units, hampering extensive sugar consumption for fungal growth. As an example, $\beta$ glucosidases, $\beta$-xylosidases, and $\alpha$-glucuronidases, or proteins included in their GHs families (such as GH1, GH3, GH4, GH30, GH43, GH51, and GH115) were not detected in the secretome of I. lacteus from SSF cultures, or were detected as minor proteins. The positive effect on glucose yields of adding $\mathrm{Mn}^{2+}$ to the cultures could be explained from two findings: the release of several isoforms of cellulase showed some degree of inhibition, which probably caused a decrease in cellulose degradation and consumption, and the induction of MnP that presumably produced an enhancement in cellulose accessibility during the enzymatic hydrolysis. 
Table 4 Diversity of GH families returned by JGI and Uniprot databases from the secretomes analyzed

\begin{tabular}{|c|c|c|c|c|c|c|c|c|c|c|c|c|c|c|c|c|c|c|c|c|c|c|c|c|c|c|c|c|c|c|c|c|c|c|c|c|c|c|c|c|c|}
\hline \multirow{2}{*}{$\frac{\text { Organism }}{\text { I. lacteus }}$} & \multicolumn{16}{|c|}{ Culture } & \multicolumn{25}{|c|}{ Glycoside hydrolase families } \\
\hline & SSF & & 2 & $3^{*}$ & & 5 & 6 & 7 & & 10 & & & & & & & & & & & & & & 35 & & $43^{*}$ & & & & 61 & & & 74 & & & & & $92^{*}$ & & & \\
\hline 1. lacteus & $\mathrm{SmF}$ & & 2 & 3 & & 5 & & & & & & & & 15 & & & & & & & & 30 & 31 & 35 & & $43^{*}$ & & & & & & & & & & & & $92^{*}$ & & & 125 \\
\hline P. chrysosporium & SSF & & & 3 & & 5 & 6 & 7 & 8 & 10 & 11 & 12 & & 15 & & 17 & 18 & 20 & 25 & 27 & 28 & 30 & 31 & 35 & 37 & 43 & 47 & & & 61 & 71 & & & & & & 88 & & & & \\
\hline P. ostreatus & SSF & 1 & 2 & 3 & 4 & 5 & 6 & 7 & 8 & 10 & & 12 & 13 & 15 & 16 & & & 20 & & 27 & 28 & & 31 & 35 & 37 & & 47 & 51 & 55 & & & 72 & & 76 & 78 & 79 & 88 & 92 & 105 & 115 & \\
\hline \multicolumn{42}{|l|}{$\begin{array}{l}\text { Type of enzymes }{ }^{1} \\
\text { Cellulose degrading enzymes }\end{array}$} \\
\hline Cellulases & & & & & & & & & x & & & & & & & & & & & & & & & & & & & & & & & & & & & & & & & & \\
\hline Endo-1,4- $\beta$-glucanases & & & & $x$ & & $x$ & & $x$ & & & & $x$ & & & $x$ & & & & & & & & & & & & & $x$ & & & & & $x$ & & & & & & & & \\
\hline Cellobiohydrolases & & & & & & & $x$ & $x$ & & $x$ & & & & & & & & & & & & & & & & & & & & & & & $x$ & & & & & & & & \\
\hline Exo-1,4- $\beta$-glucanases & & $x$ & & $x$ & & & $x$ & & & & & & & & & & & & & & & & & & & & & & & & & & & & & & & & & & \\
\hline$\beta$-Glucosidases & & $x$ & & $x$ & & & & & & & & & & & & & & & & & & $x$ & & & & & & & & & & & & & & & & & & & \\
\hline \multicolumn{42}{|l|}{$\begin{array}{l}\text { Hemicellulose degrading } \\
\text { enzymes }\end{array}$} \\
\hline Xylanases/xyloglucanases & & & & & & $x$ & & & & $x$ & $x$ & $x$ & & & & $x$ & & & & & & & & & & $x$ & & & & & & & $x$ & $x$ & & & & & & & \\
\hline Endo-1,4- $\beta$-xylanases & & & & $x$ & & $x$ & & & $x$ & & & & & & $x$ & & & & & & & & & & & & & & & & & & & & & & & & & & \\
\hline Endo-1,3- $\beta$-xylanases & & & & & & & & & & $x$ & & & & & & & & & & & & & & & & $x$ & & & & & & & & & & & & & & & \\
\hline$\beta$-Xylosidases & & & & & & & & & & & & & & & & & & & & & & $x$ & & & & $x$ & & & & & & & & & & & & & & & \\
\hline Arabinofuranosidases & & & & $x$ & & & & & & & & & & & & & & & & & & & & & & $x$ & & $x$ & & & & & & & & & & & & & \\
\hline a- Glucuronidases & & & & & $x$ & & & & & & & & & & & & & & & & & & & & & & & & & & & & & & & $x$ & & & & $x$ & \\
\hline$\beta$-Galactosidases & & $x$ & $x$ & & & & & & & & & & & & & & & & & & & & & $x$ & & & & & & & & & & & & & & & & & \\
\hline$\beta$-Mannosidases & & $x$ & $x$ & & & $x$ & & & & & & & & & & & & & & & & & & & & & & & & & & & & & & & & & & & \\
\hline Starch degrading enzymes & & & & & & & & & & & & & $x$ & $x$ & & & & & & & & & $x$ & & & & $x$ & & & & & & & & & & & & & & \\
\hline Other $\mathrm{GHs}^{2}$ & & $x$ & $x$ & $x$ & $x$ & $x$ & $x$ & $x$ & $x$ & & & $x$ & & & & $x$ & $x$ & $x$ & $x$ & $x$ & $x$ & $X$ & & $x$ & $x$ & $x$ & & $x$ & $x$ & $x$ & $x$ & $x$ & & $x$ & $x$ & $x$ & $x$ & $x$ & $x$ & $x$ & $x$ \\
\hline
\end{tabular}

Crosses (X) show the GH family to which the proteins identified in the different secretomes belong, according to http://www.cazy.org/Glycoside-Hydrolases.htm

$(*)$ These GH families were not detected in I. lacteus' spots, but were identified from EPP analyses.

(') Each functional group contains the most representative enzymes.

(2) This group contains activities different to those detailed in the Table. 


\section{Conclusions}

The current work describes for the first time the composition of the secretome of I. lacteus growing on wheat straw. The protein pattern secreted during SSF fungal growth justifies the fitness of this species for biopretreatment processes in 2G-ethanol production and provides insight into these biological processes. The secretome of I. lacteus can be of interest to be used for pretreatment of lignocellulosic material or enzymatic hydrolysis improvement through the preparation of optimized enzyme-cocktails. Due to the potential of I. lacteus in these processes, this fungus may warrant consideration in future genome projects.

\section{Methods}

\section{Fungal strains and culture media}

The white-rot fungi used in the present study were obtained from different fungal collections. I. lacteus Fr. 238 617/93 was provided from the Culture Collection of Basidiomycetes from the Academy of Sciences of the Czech Republic (CCBAS, Prague). P. chrysosporium CBS 481.73 and $P$. ostreatus CBS 411.71 were obtained from the Centraalbureau voor Schimmelcultures (CBS, Baarn, The Netherlands). The fungal species were maintained on $2 \%$ malt extract agar (MEA) tubes at $4^{\circ} \mathrm{C}$. Prior to the experiments, the three fungi were grown at $28^{\circ} \mathrm{C}$ during 7 days on MEA plates. Four agar plugs of $1-\mathrm{cm}^{2}$ were excised, inoculated into $250 \mathrm{~mL}$ Erlenmeyer flasks with $30 \mathrm{~mL}$ of growth medium (pH 5.6) and incubated at $28^{\circ} \mathrm{C}$, and $180 \mathrm{rpm}$ for 7 days. The corn-step solids growth medium (CSS) used contained $\left(\mathrm{L}^{-1}\right)$ : corn steep solids, 26.3 g; glucose, 40 g; $\mathrm{FeSO}_{4} \times 7 \mathrm{H}_{2} \mathrm{O}, 0.4 \mathrm{~g} ;\left(\mathrm{NH}_{4}\right)_{2} \mathrm{SO}_{4}, 9$ g; $\mathrm{KH}_{2} \mathrm{PO}_{4}, 4 \mathrm{~g} ; \mathrm{CaCO}_{3}, 7 \mathrm{~g}$. Each culture was aseptically homogenized (Omnimixer, Sorvall), and $2.5 \mathrm{~mL}$ were added to $250 \mathrm{~mL}$ flasks with $30 \mathrm{~mL}$ of CSS, incubating for 5 days as described above. These cultures were used as inocula for (1) solid state fermentation cultures (SSF) of the three fungal species and (2) submerged fermentation $(\mathrm{SmF}) \mathrm{cul}-$ tures of I. lacteus.

\section{SSF cultures and secretome extraction}

Wheat (Triticum aestivum) straw, harvested from Galicia fields (Spain) and composed of 36.9\% cellulose and 23\% hemicellulose (18\% xylan, $3.4 \%$ arabinan, $1.1 \%$ mannan, and $0.5 \%$ galactan), was chopped into fragments smaller than $1 \mathrm{~cm} .100 \mathrm{~mL}$ Erlenmeyer flasks containing two grams of this substrate and distilled water $(6 \mathrm{~mL})$ were autoclaved at $121^{\circ} \mathrm{C}$ for $15 \mathrm{~min}$, inoculated with 5-day-old mycelium from the different fungi $(2 \mathrm{~mL})$ and incubated at $28^{\circ} \mathrm{C}$ as previously described [3]. Non-inoculated samples were kept under the same conditions to be used as controls. The cultures of $P$. ostreatus and $P$. chrysosporium were collected after 21-d incubation. I. lacteus cultures were sampled after 7, 14 and 21 days. In parallel, $\mathrm{MnSO}_{4}$ $(0.3 \mathrm{mM})$ was added to wheat straw before autoclaving and then the flasks were incubated with I. lacteus for 21-d as detailed above. All cultures were performed in duplicate. After SSF, the cultures were extracted with water $(15 \mathrm{~mL})$ at $4^{\circ} \mathrm{C}$ and $180 \mathrm{rpm}$ for $2 \mathrm{~h}$, and filtered under vacuum to separate the solid fraction from the watersoluble components. Liquid samples were dialyzed by centrifugation with 30 volumes of Milli-Q water using 3-kDa cutoff Amicon Ultra centrifugal filter units (Millipore Corporation) and then freeze-dried for further protein isolation.

\section{SmF cultures of $I$. lacteus and secretome extraction}

Submerged cultures were performed in triplicate in $250 \mathrm{~mL}$ flasks with $30 \mathrm{~mL}$ CSS. 21-d cultures were harvested and filtered to separate the mycelium. Then the culture broth was vacuum-filtered through $0.22 \mu \mathrm{m}$ membranes (Millipore Corporation), dialyzed against water under continuous stirring at $4^{\circ} \mathrm{C}$ in a tangential ultra-filtration system (Amicon, Millipore Corporation) using a 3-kDa cutoff membrane and freeze-dried for further protein isolation.

\section{Preparation of protein extracts from SSF and SmF cultures}

Freeze-dried samples from SSF and SmF samples were resuspended in water and precipitated using the methanol/chloroform protocol to remove salts, sugars and other impurities [40]. Pellets were dried and resuspended in different solutions depending on the subsequent analysis method, as described below. Protein concentration was estimated using the RC DC Protein Assay kit from Bio-Rad.

\section{Secretome analysis}

Two different approaches were followed to study the fungal secretomes: (1) Two dimensional-polyacrylamide gel electrophoresis (2D-PAGE), followed by tryptic digestion of each spot and nanoLC-MS/MS analysis of the peptides and (2) shotgun analysis of the EPP, consisting on the tryptic digestion of the unfractionated EPP and nanoLC-MS/MS analysis of the peptides released.

\section{D-electrophoresis}

Samples from SSF and SmF cultures of I. lacteus were individually analyzed in 2D-gels. The instruments, products and methods detailed in this section were those recommended by Bio-Rad unless otherwise stated. Protein pellets were resuspended in a sample solution containing $7 \mathrm{M}$ urea, $2 \mathrm{M}$ thiourea, $4 \%(\mathrm{w} / \mathrm{v})$ CHAPS, and $0.0003 \%(\mathrm{w} / \mathrm{v})$ bromophenol blue. For isoelectrofocusing (IEF), $140 \mu \mathrm{L}$ of sample solution containing around $30 \mu \mathrm{g}$ total protein, $18.2 \mathrm{mM}$ dithiotreitol (DTT), and $0.5 \%$ immobilized $\mathrm{pH}$ gradient buffer solution were loaded into $7 \mathrm{~cm}$ non linear $\mathrm{pH} 3-$ 10 strips. 
The first dimension was run in a Protean IEF Cell system. After IEF, the strips were equilibrated, and the focused proteins reduced and alkylated, by immersion for $15 \mathrm{~min}$ in $2 \mathrm{~mL}$ equilibration buffer (50 mM Tris$\mathrm{HCl} \mathrm{pH} \mathrm{8.8,2 \%} \mathrm{[w/v]} \mathrm{sodium} \mathrm{dodecylsulfate} \mathrm{[SDS],} 6 \mathrm{M}$ urea, 30\% [v/v] glycerol) containing $52 \mathrm{mM}$ dithiothreitol (DTT), and then for 15 min the same buffer containing $130 \mathrm{mM}$ iodoacetamide. The strips were applied on $12 \%$ SDS-gels and the second dimension was run in a cooled Mini-Protean 3 Dodeca Cell at 0.5 watts/gel for $30 \mathrm{~min}$ and then at 1.5 watts/gel until the die-front reached the bottom edge (approximately $1 \mathrm{~h}$ ). As molecular mass markers, $2 \mu \mathrm{L}$ Precision Plus Protein Unstained Standards were used.

Gels were stained with SYPRO Ruby protein gel stain. An EXQuest Spot Cutter was used for image acquisition and spots picking. Gel pieces $\left(1 \mathrm{~mm}^{2}\right)$ from $2 \mathrm{D}$-spots of the 21-d SSF I. lacteus secretome (Figure 1c) and the differential spots from $\mathrm{Mn}^{2+}$-supplemented cultures (Figure 1d) and submerged cultures (Figure 1e) were excised. Fragments were rehydrated for $45 \mathrm{~min}$ at $4^{\circ} \mathrm{C}$ with a solution containing $12.5 \mathrm{ng} / \mu \mathrm{L}$ sequencing grade modified trypsin (Promega) in $50 \mathrm{mM}$ ammonium bicarbonate, and then incubated overnight at $30^{\circ} \mathrm{C}$ in the same solution. The supernatant was removed and kept, and the fragments washed for $20 \mathrm{~min}$ at room temperature with $100 \%$ acetonitrile and then with $0.5 \%$ trifluoroacetic acid (TFA). All supernatants were pooled together, dried by vacuum centrifugation and reconstituted in $0.1 \%$ TFA.

\section{EPP analysis}

The secretomes from $I$. lacteus, $P$. ostreatus, and $P$. chrysosporium 21-d SSF cultures, and from submerged cultures of $I$. lacteus, contained variable amounts of pigmented substances that could interfere with the LCMS/MS analysis of the EPP. To clean the samples, the protein pellets were dissolved in sample buffer $(37.5 \mathrm{mM}$ Tris- $\mathrm{HCl} \mathrm{pH} \mathrm{8,} \mathrm{1.5 \%} \mathrm{[w/v]} \mathrm{SDS,} 1$ mM EDTA, $1.96 \mathrm{mM}$ DTT, $0.005 \%[\mathrm{w} / \mathrm{v}]$ bromophenol blue and $12.5 \%[\mathrm{v} / \mathrm{v}]$ glycerol). Aliquots containing around $5 \mu \mathrm{g}$ of protein in a total volume of $15 \mu \mathrm{L}$ were denatured at $100^{\circ} \mathrm{C}$ for 15 min and run into a $12 \%$ SDS-gel. Prestained molecular mass markers were run in parallel. All markers were individually visualized after a short run of approximately $10 \mathrm{~min}$ at $25 \mathrm{~mA}$ in the stacking gel and $7 \mathrm{~min}$ at $20 \mathrm{~mA}$ in the resolving gel, and then the electrophoresis was stopped and the gel stained with Colloidal Blue Stain (Invitrogen). The protein gel fragment was horizontally cut into 3 similar fragments, which were excised into small pieces $\left(1 \mathrm{~mm}^{2}\right)$, destained, and reduced and alkylated as previously described. After washing and drying, the three samples were separately digested with trypsin as explained before, and then pooled again to analyze the tryptic peptides mixture. Prior to identification, samples were purified with C18-ZipTips (Millipore Corporation), eluting with $70 \%$ acetonitrile in $50 \mathrm{mM}$ ammonium bicarbonate, and dried by vacuum centrifugation.

\section{Peptide analysis by nanoLC-MS/MS}

Peptide mixtures from enzymatic digestions were dissolved in $5 \mu \mathrm{L}$ solution $\mathrm{A}(0.1 \%$ formic acid in $2 \%$ acetonitrile), and analyzed by nanoLC-MS/MS in a nanoEasy-HPLC (Proxeon) coupled to a nanoelectrospay ion source (Proxeon). Peptides were loaded onto a C18-A1 $2 \mathrm{~cm}$ precolumn (Thermo Scientific EASY-Column) and then eluted onto a Biosphere C18 capillary column (inner diameter $75 \mu \mathrm{m}, 16 \mathrm{~cm}$ long, $3 \mu \mathrm{m}$ particle size, Nanoseparations) at a flow-rate of $250 \mathrm{~nL} / \mathrm{min}$ using solutions $\mathrm{A}$ and $\mathrm{B}$ ( $0.1 \%$ formic acid in pure acetonitrile). Spots from 2D-gels were separated using the following gradient: $40 \mathrm{~min}$ from 0-35\% Buffer $\mathrm{B}$, and $5 \mathrm{~min}$ from $35-45 \%$ Buffer B. For shotgun analysis, the peptides from EPP digestions were eluted with a gradient including 55 min from $0-35 \%$ Buffer $\mathrm{B}$, and $16 \mathrm{~min}$ from $35-45 \%$ Buffer B. Full-scan MS spectra (m/z 300-1700) were acquired on an LTQ-Orbitrap Velos (Thermo Scientific) in the positive ion mode. The 15 most intense ions were selected for collision induced dissociation (CID) fragmentation in the LTQ Velos. Mass spectra files were searched against databases from Uniprot (http://www.uniprot.org/) and the Joint Genome Institute (JGI) (http://genome.jgi. doe.gov/programs/fungi/index.jsf) using the SEQUEST and MASCOT search engines through Proteome Discoverer (version 1.3.0.339, Thermo). Basidiomycota databases from Uniprot and JGI were used for I. lacteus homology queries since there is not a complete database of this fungus. In contrast, specific databases of $P$. chrysosporium and $P$. ostreatus from JGI and Uniprot were used for further peptide identification. Search parameters included a maximum of two missed cleavages allowed, carbamidomethylation of cysteines as a fixed modification and oxidation of methionine as a variable modification. The peptides were validated through the algorithm Percolator (FDR 0.05) and only those with high and medium confidence were admitted. Unless otherwise specified, protein identifications were accepted if they contained at least two identified peptides.

\section{Additional file}

Additional file 1: Table S1. Protein identification from 2D-gels of the $I$. lacteus secretomes under SSF and SmF conditions. All matches returned by $\mathrm{JGl}$ and Uniprot are given, ordered according to maximal score in each database. UP= Unique peptides; *Proteins already annotated in JGI. Tables S2 and S3. Functional classification of proteins from the complete secretome of I. lacteus growing on wheat straw after search against the Basidiomycota databases of Uniprot (S2) and JGI (S3). Tables S4 and S5. Functional classification of proteins from the complete secretome of I. lacteus growing on CSS SmF cultures after search against 
the Basidiomycota databases of Uniprot (S4) and JGI (S5). Tables S6 and S7. Functional classification of proteins from the secretome of P. chrysosporium growing on wheat straw, after search against the Basidiomycota databases of Uniprot (S6) and JGl (S7). Tables S8 and S9. Functional classification of proteins from the secretome of $P$. ostreatus growing on wheat straw after search against the Basidiomycota databases of Uniprot (S8) and JGI (S9).

\section{Abbreviations}

$\mathrm{CBH}$ : Cellobiohydrolase; CDH: Cellobiose dehydrogenase; DyP: Dyedecolorizing peroxidase; EPP: Extracellular pool of proteins; GH: Glycoside hydrolase; IEF: Isoelectric focusing; LiP: Lignin peroxidase; MM: Molecular mass; MnP: Manganese peroxidase; nanoLC-MS/MS: nano liquid chromatography-tandem mass spectrometry; pl: Isoelectric point; SDS: Sodium dodecylsulfate; SmF: Submerged fermentation; SSF: Solid state fermentation; VP: Versatile peroxidase.

\section{Competing interests}

The authors declare that they have no competing interests.

\section{Authors' contributions}

DS participated in the design of the study, carried out the experiments, organized and interpreted the data, and drafted the manuscript. MT made substantial contributions to conception of the initial experiments. MF, FG-T, and VR performed the proteomics experiments. ATM revised critically the manuscript with substantial contribution to its intellectual content. MJM and AP participated in the design, coordination, and data analysis of the study, and corrected the manuscript. All authors read and approved the final manuscript.

\section{Acknowledgements}

This work has been carried out with funding from the Spanish project PRIPIBAR-2011-1402 and the PEROXICATS European project. D. Salvachúa thanks the Spanish Ministry of Economy for a FPU fellowship and to Prashanti lyer and the Proteomics Facility in Penn State University for their assistance during her pre-doctoral stay. The authors thank CSIC for financial support for open access publication.

\section{Author details}

${ }^{1}$ Centro de Investigaciones Biológicas, CSIC, Ramiro de Maeztu 9, E-28040 Madrid, Spain. ${ }^{2}$ Department of Biochemistry and Molecular Biology, Pennsylvania State University, University Park PA, 16802 USA.

\section{Received: 7 June 2013 Accepted: 6 August 2013}

Published: 10 August 2013

\section{References}

1. Martínez AT, Speranza M, Ruiz-Dueñas FJ, Ferreira P, Camarero S, Guillén F, Martínez MJ, Gutiérrez A, del Río JC: Biodegradation of lignocellulosics: microbiological, chemical and enzymatic aspects of fungal attack to lignin. Int Microbiol 2005, 8:195-204.

2. Lee J: Biological conversion of lignocellulosic biomass to ethanol. J Biotechnol 1997, 56:1-24.

3. Salvachúa D, Prieto A, López-Abelairas M, Lu-Chau T, Martínez AT, Martínez MJ: Fungal pretreatment: an alternative in second-generation ethanol from wheat straw. Bioresour Technol 2011, 102:7500-7506.

4. Xu C, Ma F, Zhang X, Chen S: Biological pretreatment of corn stover by Irpex lacteus for enzymatic hydrolysis. J Agric Food Chem 2010, 58:10893-10898.

5. Pinto PA, Dias AA, Fraga I, Marques G, Rodrigues MAM, Colaco J, Sampaio A, Bezerra RMF: Influence of ligninolytic enzymes on straw saccharification during fungal pretreatment. Bioresour Technol 2012, 111:261-267.

6. Du W, Yu H, Song L, Zhang J, Weng C, Ma F, Zhang X: The promoting effect of byproducts from Irpex lacteus on subsequent enzymatic hydrolysis of bio-pretreated cornstalks. Biotech Biofuels 2011, 4:37.

7. Salvachúa D, Prieto A, Vaquero ME, Martinez AT, Martínez MJ: Sugar recoveries from wheat straw following treatments with the fungus Irpex lacteus. Bioresour Technol 2013, 131:218-225.
8. Song $L, M a F$, Zeng $Y$, Zhang $X, Y u H$ : The promoting effects of manganese on biological pretreatment with Irpex lacteus and enzymatic hydrolysis of corn stover. Bioresour Technol 2013, 135:89-92.

9. Bouws H, Wattenberg A, Zorn H: Fungal secretomes - nature's toolbox for white biotechnology. Appl Microbiol Biotechnol 2008, 80:381-388.

10. Couturier M, Navarro D, Olive C, Chevret D, Haon M, Favel A, Lesage-Meessen L, Henrissat B, Coutinho PM, Berrin JG: Post-genomic analyses of fungal lignocellulosic biomass degradation reveal the unexpected potential of the plant pathogen Ustilago maydis. BMC Genomics 2012, 13:57.

11. Ravalason H, Grisel S, Chevret D, Favel A, Berrin JG, Sigoillot JC, HerpoelGimbert l: Fusarium verticillioides secretome as a source of auxiliary enzymes to enhance saccharification of wheat straw. Bioresour Technol 2012, 114:589-596.

12. Ribeiro DA, Cota J, Alvarez TM, Bruechli F, Bragato J, Pereira BM, Pauletti BA, Jackson G, Pimenta MT, Murakami MT, Camassola M, Ruller R, Dillon AJ, Pradella JG, Paes Leme AF, Squina FM: The Penicillium echinulatum secretome on sugar cane bagasse. Plos One 2012, 7:12e50571. doi:10.1371/ journal.pone.0050571.

13. Abbas $\mathrm{A}, \mathrm{Koc} \mathrm{H}$, Liu F, Tien M: Fungal degradation of wood: initial proteomic analysis of extracellular proteins of Phanerochaete chrysosporium grown on oak substrate. Curr Genetics 2005, 47:49-56.

14. Sato S, Liu F, Koc H, Tien M: Expression analysis of extracellular proteins from Phanerochaete chrysosporium grown on different liquid and solid substrates. Microbiology-SGM 2007, 153:3023-3033.

15. Vanden Wymelenberg A, Sabat G, Martínez D, Rajangam AS, Teeri T, Gaskell J, Kersten PJ, Cullen D: The Phanerochaete chrysosporium secretome: Database predictions and initial mass spectrometry peptide identifications in cellulose-grown medium. J Biotechnol 2005, 118:17-34.

16. Martínez D, Larrondo LF, Putnam N, Gelpke MD, Huang K, Chapman J, Helfenbein KG, Ramaiya P, Detter JC, Larimer F, Coutinho PM, Henrissat B, Berka R, Cullen D, Rokhsar D: Genome sequence of the lignocellulose degrading fungus Phanerochaete chrysosporium strain RP78. Nat Biotechnol 2004, 22:695-700.

17. Zorn H, Peters T, Nimtz M, Berger RG: The secretome of Pleurotus sapidus. Proteomics 2005, 5:4832-4838.

18. Mahajan S, Master ER: Proteomic characterization of lignocellulosedegrading enzymes secreted by Phanerochaete carnosa grown on spruce and microcrystalline cellulose. App/ Microbiol Biotechnol 2010, 86:1903-1914.

19. Manavalan T, Manavalan A, Thangavelu KP, Heese K: Secretome analysis of Ganoderma lucidum cultivated in sugarcane bagasse. J Proteomics 2012, 77:298-309.

20. Ji XL, Zhang WT, Gai YP, Lu BY, Yuan CZ, Liu QX, Mu ZM: Patterns of lignocellulose degradation and secretome analysis of Trametes trogii MT. Int Biodet Biodegr 2012, 75:55-62.

21. Yang F, Jensen JD, Svensson B, Jorgensen HJ, Collinge DB, Finnie C: Secretomics identifies Fusarium graminearum proteins involved in the interaction with barley and wheat. Mol Plant Pathol 2012, 13:445-453.

22. Sánchez C: Lignocellulosic residues: biodegradation and bioconversion by fungi. Biotechnol Advances 2009, 27:185-194.

23. van den Brink J, de Vries RP: Fungal enzyme sets for plant polysaccharide degradation. Appl Microbiol Biotechnol 2011, 91:1477-1492.

24. Kersten P, Cullen D: Extracellular oxidative systems of the lignindegrading Basidiomycete Phanerochaete chrysosporium. Fungal Genet Biol 2007, 44:77-87.

25. de Oliveira AL, Gallo M, Pazzagli L, Benedetti CE, Cappugi G, Scala A, Pantera B, Spisni A, Pertinhez TA, Cicero DO: The structure of the elicitor ceratoplatanin $(\mathrm{CP})$, the first member of the $\mathrm{CP}$ fungal protein family, reveals a double psi b-barrel fold and carbohydrate binding. J Biol Chem 2011, 286:17560-17568.

26. Novotny C, Cajthaml T, Svobodova K, Susla M, Sasek V: Irpex lacteus, a white-rot fungus with biotechnological potential - review. Folia Microbiol 2009, 54:375-390.

27. Espino JJ, Gutierrez-Sanchez G, Brito N, Shah P, Orlando R, Gonzalez C: The Botrytis cinerea early secretome. Proteomics 2010, 10:3020-3034.

28. Nagasaki K, Kumazawa M, Murakami S, Takenaka S, Koike K, Aoki K Purification, characterization, and gene cloning of Ceriporiopsis sp strain MD-1 peroxidases that decolorize human hair melanin. Appl Environ Microbiol 2008, 74:5106-5112

29. Tsumuraya Y, Mochizuki N, Hashimoto Y, Kovac P: Purification of an ExoBeta-( $1 \rightarrow 3)$-D-galactanase of Irpex lacteus (Polyporus tulipiferae) and its action on arabinogalactan proteins. J Biol Chem 1990, 265:7207-7215. 
30. Salvachúa D, Prieto A, Martinez AT, Martinez MJ: Characterization of a novel DyP-type peroxidase from Irpex lacteus and its application in the enzymatic hydrolysis of wheat straw. Appl Environ Microbiol 2013, 79:4316-4324.

31. Camarero S, Sarkar S, Ruiz-Dueñas FJ, Martínez MJ, Martínez AT: Description of a versatile peroxidase involved in natural degradation of lignin that has both $\mathrm{Mn}$-peroxidase and lignin-peroxidase substrate binding sites. J Biol Chem 1999, 274:10324-10330.

32. Gómez-Toribio V, Martínez AT, Martínez MJ, Guillén F: Oxidation of hydroquinones by the versatile ligninolytic peroxidase from Pleurotus eryngii: $\mathrm{H}_{2} \mathrm{O}_{2}$ generation and the influence of $\mathrm{Mn}^{2+}$. Eur J Biochem 2001, 268:4787-4793.

33. Vanden Wymelenberg A, Minges P, Sabat G, Martínez D, Aerts A, Salamov A, Grigoriev I, Shapiro H, Putnam N, Belinky P, Dosoretz C, Gaskell J, Kersten P, Cullen D: Computational analysis of the Phanerochaete chrysosporium v2.0 genome database and mass spectrometry identification of peptides in ligninolytic cultures reveal complex mixtures of secreted proteins. Fungal Genet Biol 2006, 43:343-356.

34. Maclntosh GC: RNase T2 family: enzymatic properties, functional diversity, and evolution of ancient ribonucleases. In Ribonucleases, Nucleic Acids and Molecular Biology. Volume 26. Edited by Nicholson AW. Berlin Heidelberg: Springer-Verlag; 2011:89-114.

35. Scheibner M, Hulsdau B, Zelena K, Nimtz M, de Boer L, Berger RG, Zorn H: Novel peroxidases of Marasmius scorodonius degrade b-carotene. Appl Microbiol Biotechnol 2008, 77:1241-1250.

36. Ravalason H, Jan G, Molle D, Pasco M, Coutinho PM, Lapierre C, Pollet B, Bertaud F, Petit-Conil M, Grisel S, Sigoillot JC, Asther M, Herpoël-Gimbert I: Secretome analysis of Phanerochaete chrysosporium strain CIRM-BRFM41 grown on softwood. Appl Microbiol Biotechnol 2008, 80:719-733.

37. Jovanovic I, Magnuson JK, Collart F, Robbertse B, Adney WS, Himmel ME, Baker SE: Fungal glycoside hydrolases for saccharification of lignocellulose: outlook for new discoveries fueled by genomics and functional studies. Cellulose 2009, 16:687-697.

38. Gregg KJ, Zandberg WF, Hehemann JH, Whitworth GE, Deng L, Vocadlo DJ, Boraston AB: Analysis of a new family of widely distributed metalindependent a-mannosidases provides unique insight into the processing of N-linked glycans. J Biol Chem 2011, 286:15586-15596.

39. Harris PV, Welner D, MCFarland K, Re E, Poulsen JCN, Brown K, Salbo R, Ding H, Vlasenko E, Merino S, Xu F, Cherry J, Larsen S: Lo Leggio L: stimulation of lignocellulosic biomass hydrolysis by proteins of glycoside hydrolase family 61: structure and function of a large, enigmatic family. Biochemistry 2010, 49:3305-3316.

40. Wessel $D$, Flugge UI: A method for the quantitative recovery of protein in dilute-solution in the presence of detergents and lipids. Anal Biochem 1984, 138:141-143.

doi:10.1186/1754-6834-6-115

Cite this article as: Salvachúa et al:: Differential proteomic analysis of the secretome of Irpex lacteus and other white-rot fungi during wheat straw pretreatment. Biotechnology for Biofuels 2013 6:115.

\section{Submit your next manuscript to BioMed Central and take full advantage of:}

- Convenient online submission

- Thorough peer review

- No space constraints or color figure charges

- Immediate publication on acceptance

- Inclusion in PubMed, CAS, Scopus and Google Scholar

- Research which is freely available for redistribution 